International Journal of Linguistics, Literature and Translation

ISSN: 2617-0299 (Online); ISSN: 2708-0099 (Print)

DOI: $10.32996 /$ ijllt

Journal Homepage: www.al-kindipublisher.com/index.php/ijltt

\title{
Comparative Move Analysis of Chinese and English Product Description on eBay
}

\author{
Tang Lei \\ Postgraduate student, School of Foreign Languages, Jiangxi University of Finance and Economics, NanchangJiangxi, China
}

$\square$ Corresponding Author: Prof Zhang Xifeng, E-mail: 1846500350@qq.com

\begin{abstract}
ARTICLE INFORMATION ABSTRACT

Received: 15 September 2021

Accepted: 16 October 2021

Published: 30 October 2021

DOI: 10.32996/ijllt.2021.4.10.16

Based on the move analysis theory of the ESP school, this research selects 10 product description pages of both Chinese and American e-stores on the international ecommerce platform eBay as the corpus of this paper. Quantitative analysis is used to compare the distinctive move structures of the product description in Chinese and American e-stores in order to find out the similarities and differences of moves

\section{KEYWORDS}

eBay, Move analysis, Product description, ESP teaching. employed between different countries and try to give explanations for the reasons behind these differences from the perspective of cross-cultural communication. The results of this paper can be regarded as a valuable resource for those online shoppers from both China and America so that they can have a better idea to edit the product detail page and it is hoped that this paper could also provide some inspiration on the ESP teaching.
\end{abstract}

\section{Introduction \\ 1.1 Overview}

The global economic and social pattern has changed a lot in a few years, thanks to the emergence and popularization of ecommerce. This kind of business pattern is about using computer networks to conduct business like buying, selling, exchanging products, services, and information (McKay and Marshall, 2004). As online channels are becoming more and more convenient and available for business worldwide, an increasing number of international customers would choose to purchase on various crossborder e-commerce platforms, such as Amazon, Alibaba, and eBay. Among them, eBay was founded in 1995 and is the world's earliest cross-border e-commerce platform.

\subsubsection{A Brief Introduction of eBay}

eBay Inc (eBay) is a multinational online retailing marketplace that connects buyers and sellers in 190 countries all around the globe. This e-commerce platform enables buyers to access a broad range of inventory and sellers to arrange and offer their inventory for sale, digitally. In its official report of the third quarter in 2020, it had 183 million active buyers worldwide and more than 1.6 billion living product listings on this e-commerce platform. As one of the most successful C2C (customer-to-customer or citizen-to-citizen) websites in the world, eBay did remarkable work since its foundation. The total amount of eBay revenue of the third quarter in 2020 was $\$ 2.6$ billion. Among its 190 markets around the world, the USA market remains to be the largest for it has the highest overall Global Marketplace Index score and it accounts for $40 \%$ of overall net revenue in 2019. The eBay US site is the largest and most important eBay site. Products sold by U.S. sellers are ranked first in the display of live product listings and search results. Meanwhile, China, as the largest developing country and emerging market in the world, is gaining momentum in the development of cross-border e-commerce, more and more cross-border e-commerce platforms have tried to look for more benefits from this ocean of fortune.

The COVID-19 pandemic has caused social and economic disruption around the world, including the largest global recession since the Great Depression, leading to the closedown of plentiful small and middle-sized enterprises, the traditional foreign trade industry globally has all suffered a continuous depression. On such a tough occasion, the importance and benefits of cross-border commerce websites like eBay have been unfolded.

Copyright: (C) 2021 the Author(s). This article is an open access article distributed under the terms and conditions of the Creative Commons Attribution (CC-BY) 4.0 license (https://creativecommons.org/licenses/by/4.0/). Published by Al-Kindi Centre for Research and Development, London, United Kingdom. 


\subsection{The Study Subject}

Since the foundation of eBay Inc. in 1995, the number of consumers who are accustomed to online consumption is getting bigger and bigger. Unlike traditional offline shopping, customers could only perceive the quality of products through words and pictures put on the product description, instead of concrete watching and touching. Pictures could only show the image of the product. However, the style, properties, and selling points of the product, in order to cater to the emotional appeal of consumers, require written words to explain and elaborate. Therefore, the product description plays an indispensable and irreplaceable role in the product detail page. The product description, or product page detail, is a page for e-commerce stores to display product information, detail, and selling points. As the one and only channel for consumers to acquire product information, detail pages act as a bridge between customers and products online. A splendid product description page could exert an active effect on activating customers' buying behavior, it could also stimulate customers' desire to consume and build their trust in one particular e-store and then motivate them to place their order.

The main three functions of the product detail page are as follows: firstly, it is a brief introduction for the features, uses, and instructions of the displayed product; secondly, it takes as an advertisement for the listing product in order to entice customers to make a purchase; the third one is to compile consistent-style product detail page so as to obtain higher recognition.

From a linguistics perspective, those sentences constituting the text of the product detail page are not spoken discourse or a formal written discourse, but a monologue e-discourse with spoken and written characteristics. The editor of a product description cannot get instant feedback from customers, so editors have to convey the product information in a limited space to their targeted consumers as many as possible, therefore, as a special discourse with commercial value, the product description in those crossborder e-stores does have a great value for discourse analysis.

Using a move-step analysis, 10 product descriptions of face masks in Chinese e-stores ( in consideration of the severe COVID-19 pandemic ) and 10 of American e-stores on eBay were chosen to be analyzed respectively in this paper.

\section{Literature review}

\subsection{Previous studies on the product description}

The rapid development of the economy gives birth to the emerging of new genres in the business field, of which product description is one of the examples. Though it is a specific business genre, very little researches have been conducted on the move analysis of product description, let alone the comparison between countries with different economic developmental stage and cultural background.

Researches on the product description of cross-border e-commerce platform are also limited. Few scholars both from abroad and domestic, have done research on this. They focused more on the marketing strategies that the e-commerce platform employed.

In 1960, the original marketing mix, or 4 Ps (Product, Price, Place, and Promotion), as originally proposed by E. Jerome McCarthy of the University of Michigan, provided a basic framework for network marketing decision-making.

Domestically, since the booming growth of the Chinese e-commerce platform Taobao, much researches on product description have been concentrated mainly on e-business, marketing, and website design.

Duan Wenzhong (2014), in his book, devoted an enormous amount of detailed instruction on how to design product detail pages. In 2016, Zhong Peijun analyzed effective methods to maximize commodity conversion rate by website design.

As for the linguistic analysis of product description, Luo Yanjun (2017) in her paper held that a good product description has to attract customers by highlighting the selling points and being concise, informative, and true. In order to achieve these objectives, she also provided three writing skills: beautifully structured, design based on authentic data, using rhetorical skills like metaphor, personification, and contrast.

\subsection{Previous studies on move analysis}

From the 1980s, one of the most influential schools was the ESP school, of which Swales is the pioneer. The move analysis is based on Swales' $(1990,2004)$ view of genre theory. In his book Genre Analysis: English in Academic and Research Settings(1990), he defined the genre as "a class of communicative events, the members of which share some sets of communicative purposes". He also held that genre analysis has proven to be an effective tool for professional communication research, this analysis has developed to include the study not only of specific linguistic features but also of the social context, culture, ideology, and social practices of the discourse community. With the further development of Swales' review, Bhatia, in 1993, gave his definition of the genre, he argued that genre is a recognized communicative event characterized by a set of communicative purposes identified and mutually understood by the members of the professional and academic community in which it regularly occurs. Genre analysis or move analysis is under the scope of discourse analysis, according to Bhatia (1993). 
Nowadays, move analysis has been applied from a linguistic perspective in much academic research and ESP genres, for example, business marketing, legal document, etc. All these studies that employed this methodology were proven to be useful and effective.

In 2011, Cris Yelland made a genre and move analysis of written feedback in higher education. Alireze Bonyadi (2012) wrote in his paper to investigate the move analysis of media texts. He found out that newspaper editorials take certain moves that are usually textually realized through certain linguistic forms. In 2013, Brian Rutherford did a move or genre theoretical approach to financial reporting research. This paper discussed the moves applied in the discourse analysis and the application in financial reporting. Xu Xiaoyu and Jane Lockwood co-authored a paper in 2020, in this article, they used move analysis to investigate the steps in ecommerce customer service WeChat exchange, Nine moves have been found in their research, the rich findings have uncovered several features that can shed light on ways of improving communication for contact centers. In the same year, Matt Kessler also employed the move analysis to investigate the successful applicants to the Fulbright English Teaching Assistant (ETA) grants program, they found that most writers tended to employ a variety of rhetorical move-steps when addressing the personal statement and a statement of grant purpose prompts.

Given the shortage of informative researches on the linguistic nature of e-commerce product description and given the need in ecommerce platform for the attractive design of product description, in an effort to learn more about Sino-US similarities and differences on the product description on eBay, this paper explores the move analysis of eBay product description. This research is guided by the following three questions:

1. What are the mandatory and optional moves employed by Chinese and American cross-border e-store on the product description on eBay?

2. What are the similarities and differences of moves and steps employed by the Sino-US eBay e-store?

3. What are the reasons (mostly cultural differences) behind these differences?

Our methodology for doing this research is elaborated on below.

\section{Method}

\subsection{Data and collection}

20 product descriptions of face masks (taking COVID-19 pandemic into consideration) were collected from the international C2C e-commerce platform eBay, with 10 from Chinese e-stores and 10 from American as the corpus of this paper. All names of stores won't be displayed for privacy reasons. All these face masks sell well and come from different stores, so the result of this research could be more typical and meaningful. Because in some product detail pages, the written description part is inset in the pictures, this research would sift those words or sentences as product descriptions. And for the particularity of the cross-border e-commerce and online international trade, if a customer wanted to register an account and place an order on a cross-border e-commerce platform like eBay, the destination address has to be chosen before browsing the shopping website because some countries can not be delivered because of some e-stores' destination limits. Therefore, the destination countries were chosen to be the USA, the UK, and China in order to collect 20 corpus.

It needs to be pointed out that all product descriptions chosen as data in this paper are from website pages of cross-border estores, instead of the mobile terminal. The product detail page in the mobile phone could be further studied as another research direction.

\subsection{Move-step coding and analysis}

Because one goal of this study was to shed light on merchants' rhetorical choices, the analysis of the text in product description followed by a move-step analysis (Swales, 1990, 2004). Moves and steps are two basic structural units for genre analysis. As mentioned above, a move is operationalized using Swales' (2004) definition of a "discoursal or rhetorical unit that performs a coherent communicative function" (p228). Steps are further subdivisions of these moves, thus contributing to achieving a move's communicative function. Move analysis emphasizes more on discourse structures concerning communicative purposes and identifies discourse parts (moves) that serve coherent yet distinctive communicative purposes and functions. The application of a move-step analysis was pivotal in this study, for this method has been utilized for ESP by many scholars. A famous model for the conduction of a genre is the CARS (Create a Research Space) model put forward by Swales. This model is shown in Table 3.1 as follows 


\begin{tabular}{|l|l|}
\hline Move 1 Establishing a territory & \multicolumn{1}{|l|}{} \\
Step 1 Claiming centrality \\
Step 2 Making topic generalization(s) \\
Step 3 Reviewing items of previous research
\end{tabular}

Table 3.1. CARS model (Swales, 1990: 78)

However, Bhatia (1993) paid more attention to the texts on the business circumstance. He proposed a well-known seven-step to analyze a genre as follows:

1. Placing the given text genre in a situational context;

2. Surveying existing literature;

3. Refining the contextual analysis;

4. Selecting corpus;

5. Studying the situational context;

6. Undertaking three levels of linguistic context;

7. Specialist information in genre analysis.

Based on this genre analysis model, Bhatia proposed another seven-move model for the structure of the promotional genre,

1. Establishing credentials (obligatory)

2. Introducing the offer or candidature (obligatory)

a) Offering the product or service/candidature

b) Essential detailing of the offer/candidature

c) Indicating value of the offer/candidature

3. Offering incentives (optional)

4. Enclosing documents (optional)

5. Soliciting response (obligatory)

6. Using pressure tactics (optional)

7. Ending politely (optional) 
Bhatia is a pioneer in the construction and explanation of academic and professional genres in that he identified and classified communicative purposes of the discourse community and offered a hierarchical structure for some business discourse. (Liu Xuyang 2016)

Therefore, Swales' (1990) and Bhatia's (1993) genre theory would be applied to be the theoretical guidance for this paper. The move structures of the product description on the e-commerce platform will be summarized and revealed respectively with the quantitative method and sample analysis method. Accordingly, their similarities and differences will be drawn.

\section{Results, discussion, and analysis}

The findings relating to each question posed above are provided as follows.

\subsection{The special moves and steps of e-commerce product description}

The analysis of this paper started from reading through each sentence in every product description of face masks and identifying the sentences and components that perform the same purposes and functions of the moves and then listing them in a table, all these moves of product description would be coded twice by the same researcher. Finally, all these moves would be labeled according to the role of a sentence played in the product description. The following two models are an experiment for the analysis of the moves and steps for product descriptions of face masks, every move and step is accompanied by an example of chosen sentence constituting the description of a face mask.

An Experimental model for the analysis of the moves and steps for product description in American e-stores:

Move 1 Product Title (optional): 50 PCS BLACK FACE MASK MOUTH\&NOSE PROTECTION RESPIRATOR MASKS WITH FILTER NEW

Move 2 Product Details (mandatory)

Step 2A Quantity and Package (mandatory): 50 pcs/package

Step 2B Size and Color (mandatory): $6.89 \times 3.74 \times 0.047$ inches/Black

Step 2C Material, Design, and Main Functions (mandatory): The outer layer filters out dust, odors, and large particles, while the key melt-blown layer filters small particles.

Move 3 Product Features (mandatory)

Step 3A Superior protection (mandatory): Our dust masks come in packs of 50, which is ideal for daily use

Step 3B Our advantages compared with other face masks (optional): This is a MUCH better alternative to the low-quality masks on Amazon that are single-use only and are literally like "having just a tee-shirt on your face" according to their reviews.

Move 4 Payment (mandatory): We only accept payments through PayPal.

Move 5 Shipping (mandatory)

Step 5A Delivery Time (optional): Handling time is usually around 1-2 business days.

Step 5B Transportation (optional):USPS First-Class Ma

Move 6 Returns (optional): We offer a 30-Day Money-Back Guarantee.

Move 7 About us (mandatory)

Step 7A A brief introduction of the company (optional): Blade Addict Co. is a United States company that is based in San Francisco, California. We have been in the industry for over 10+ years and are dedicated to providing customers with high-quality outdoor products at reasonable prices.

Step 7B The hyperlinks of hot-sale products and the company (optional)

Step 7C Featured Categories of the company (optional): Blade Addict Co. is a United States company that is based in San Francisco, California. We have been in the industry for over 10+ years and are dedicated to providing customers with high-quality outdoor products at reasonable prices.

Step 7D Contact us (optional): Blade Addict Co. is a United States company that is based in San Francisco, California. We have been in the industry for over 10+ years and are dedicated to providing customers with high-quality outdoor products at reasonable prices. 
To sum up, the number of the moves of the product description in American e-store is seven in total, some moves are mandatory for they are components in every description, some are optional because some online shoppers did not employ this move.

An Experimental model for the analysis of the moves and steps for product description in Chinese e-stores:

Move 1 Product Title (mandatory)

Move 2 Product Specifications (mandatory)

Step 2A Condition and Item Name (optional):100\% Brand New \& High Quality/ Mouth Face Mask

Step 2B Color and Size (mandatory): Multi Pattern/One Size Fits Most

Step 2C Material and Suitable Gender (mandatory): Cotton/Unisex, Adult

Move 3 Product Features (mandatory)

Step 3A Design and Function (mandatory): Elastic earloop mouth-mask is wide enough to cover nose, mouth, and face, very comfortable to wear.

Step 3B Feature (optional): The mask is breathable, suitable to wear in spring and summer.

Move 4 Package (mandatory): 1 x Face Mask

Move 5 Notice (mandatory): Due to the light and screen difference, the item's color may be slightly different from the pictures. Please understand. Make sure you don't mind before you bid.

Move 6 Payment (mandatory): PayPal is the only online payment method we accept. Please make sure you have a valid/confirmed PayPal account prior to bidding.

Move 7 Shipping (mandatory)

Step 7A Delivery Time (mandatory): It takes about 15-25 days to ship worldwide.

Step 7B Transportation (mandatory): All items will be shipped by China Post Airmail.

Move 8 Returns and Refunds (mandatory): Your satisfaction is our first priority. If you don't like the item, you can return it to us. Returns are available within 14 days after you received them. All items must be returned in their original condition. After we received the items, we will refund you immediately, so please be assured. Thanks for your understanding and cooperation.

Move 9 Contact us ( mandatory): Don't hesitate to contact us through eBay message if you have any problems. We are committed to your 100\% customer satisfaction. Our working time: Beijing Time: 9:00 AM-17:30 PM (Monday Through Saturday). Except for Holiday.

It can be concluded that 9 moves are included in the product description of Chinese e-stores. However, all these sequences of moves are only a general pattern, and variations can occur in every different product description.

\subsection{Analysis for the similarities and differences between Chinese and American e-store}

According to the above move and step analysis of the Chinese and American e-store product description, it can be found that the move structures of the two countries' product descriptions online bear some resemblances and some differences. Therefore, in this part, their similar move structures and different structures will be summarized.

\subsubsection{The similarities}

By comparing the above listing two move models, it is not difficult to find out the similarities of the Sino-US e-commercial product descriptions. Both of them includes the following moves and steps:

(1) Product title

(2) Product details or specifications

(3) Product features and functions

(4) Payment

(5) Shipping, including delivery time and transportation

(6) Return 
Almost every e-store would restate their product title at the beginning of the whole product description. And this move is mandatory in the data collected.

As for the product details or specifications, such as color, size, and quantity, both Chinese and American e-store would put this move in a conspicuous place in order to offer the details of face masks for customers.

Stating the product features and functions is also a mandatory move in both Chinese and American e-store, because this is the most important part of the product description, especially for face masks during the COVID-19 pandemic.

In conclusion, all the similar moves in the product description of Chinese and American eBay e-stores are mandatory moves and steps. Because of the specificity of cross-border e-commerce, international consumers will pay more attention to see whether this information is contained in the product description.

\subsubsection{The differences}

Although the online product description of the two countries shares a great number of similarities, there still exist lots of differences between them. In order to have a clearer comparison and contrast between the product description of these two countries' estores, the following table will put the move model above together so as to have a more visual comparison.

\begin{tabular}{|c|c|}
\hline Product Description of American E-store & Product Description of Chinese E-store \\
\hline Move 1 Product Title (mandatory) & Move 1 Product Title (mandatory) \\
\hline $\begin{array}{l}\text { Move } 2 \text { Product Details (mandatory) } \\
\text { Step2A Quantity and Package (mandatory) } \\
\text { Step2B Size and Color (mandatory) } \\
\text { Step2C Material, Design, and Main Functions } \\
\text { (mandatory) }\end{array}$ & $\begin{array}{l}\text { Move } 2 \text { Product Specification (mandatory) } \\
\text { Step2A Condition, Item Name (optional) } \\
\text { Step2B Color and Size } \\
\text { Step2C Material and Suitable Gender }\end{array}$ \\
\hline $\begin{array}{l}\text { Move } 3 \text { Product Features (mandatory) } \\
\text { Step3A Superior protection (mandatory) } \\
\text { Step3B Our advantage compared with other face } \\
\text { masks (optional) }\end{array}$ & $\begin{array}{l}\text { Move } 3 \text { Product Features (mandatory) } \\
\text { Step3A Design and Function (mandatory) } \\
\text { Step3B Features (mandatory) }\end{array}$ \\
\hline Move 4 Payment (mandatory) & Move 4 Package (mandatory) \\
\hline $\begin{array}{l}\text { Move } 5 \text { Shipping (mandatory) } \\
\text { Step5A Delivery Time (optional) } \\
\text { Step5B Transportation (optional) }\end{array}$ & Move 5 Notice (mandatory) \\
\hline Move 6 Returns (optional) & Move 6 Payment (mandatory) \\
\hline $\begin{array}{l}\text { Move } 7 \text { About us (mandatory) } \\
\text { Step7A A brief introduction (optional) } \\
\text { Step7B The hyperlinks of hot-sale products and the } \\
\text { company (optional) } \\
\text { Step7C Featured Categories of the company } \\
\text { (optional) } \\
\text { Step7D Contact us (optional) }\end{array}$ & $\begin{array}{l}\text { Move } 7 \text { Shipping (mandatory) } \\
\text { Step7A Delivery Time (mandatory) } \\
\text { Step7B Transportation (mandatory) }\end{array}$ \\
\hline & Move 8 Returns and Refund (mandatory) \\
\hline & Move 9 Contact us ( mandatory) \\
\hline
\end{tabular}

Table 4.1

From this table, it can be easy to find out that Chinese e-store has two more moves than Americans.

According to table 4.1 above, it is noted that the product package detail information in the Chinese e-store is separated out as a single move, while in the American description, this move is contained in Move 2 Product Detail as a step.

And the other extra Chinese move is Move 5 Notice. Strangely, almost all product descriptions in the Chinese eBay e-store would contain a sentence to remind customers to notice the subtle difference between the real product and the pictures posted on the detail page. And this sentence is written in red with bold letters. While in an American e-store, there is no such notice or warning.

And about move 6 in American e-stores and Move 8 in Chinese e-stores, although both moves are about return, a step in Chinese description named refund is not contained in the American online product description. Chinese description prefers to provide more methods for customers to ask for refunds in order to avoid any possible negative comments which could vastly reduce estore traffic on eBay. 
It is also clear to see that in American e-store description, the hyperlinks of some hot-sale products and the companies would be added in the product description, while in Chinese e-stores' product description, the online shopper would only leave a sentence to ask consumers to contact them when there is any problem, without any contact information, only the account e-mail attached automatically. It is also interesting to see that the contact move in American e-store is optional, while in Chinese e-store, it is mandatory.

Concerning the shipping move, in the above table, there is no big difference between Sino-US online product descriptions. In fact, by comparing the realistic product description of face masks in the American and Chinese eBay e-store, it can be found that the accurate delivery time is always displayed in Chinese description for the goods would take a long period to be delivered to international consumers from China.

Another difference is that in the American website product description, the advantage of the product would be carried out in the product features move, in contrast, Chinese shoppers would not put this step on their detail page.

This table reveals great differences between the format adoption frequency of product descriptions of Chinese and Americans on eBay. While based on all the sources collected, another distinctive difference between Chinese and American online product descriptions is the frequency of the format chosen. American e-stores tend to write longer product description which often consists of several paragraphs. However, Chinese e-commerce shoppers are more likely to use a shorter and more simplified expression to make the product description

The following is the table that presents the formats adoption frequency between Chinese and American eBay stores.

\begin{tabular}{|l|l|l|l|}
\hline & Format A Word Phrases & $\begin{array}{l}\text { Format B Long } \\
\text { Sentences }\end{array}$ & Format C Paragraphs \\
\hline $\begin{array}{l}\text { The number of Chinese } \\
\text { e-stores }\end{array}$ & 5 & 5 & 0 \\
\hline $\begin{array}{l}\text { The number of } \\
\text { American e-stores }\end{array}$ & 0 & 6 & 4 \\
\hline
\end{tabular}

Table 4.2 The format adoption frequency of the product description of Chinese and American e-store on eBay

The table suggests that for the Chinese eBay stores, five e-stores adopt word phrase (Format A) to state their product description; 5 e-stores edit their product description with long sentences (Format B); as for American e-stores, 6 stores' product descriptions are presented by long sentence; while the other 4 e-stores' product description is written in several paragraphs (Format $\mathrm{C}$ ).

From the whole website design and arrangement of the online product description, it is interesting to be remarked that every American E-store on eBay has strongly distinctive features, although the moves employed are quite similar, the specific language they used is various. Those Chinese e-stores, in contrast, it is suspected that all these Chinese e-shoppers employ the same design template because the language arranged in constituting the whole product description are almost identical, even the pictures employed.

\subsection{Reasons for the similarities and differences of the moves employed by Chinese and American e-store on eBay.}

After the comparative analysis of online product descriptions of Chinese and American cross-border e-commerce platforms, it can be concluded that about six similar moves.

The data source of this paper is chosen from the international e-trade platform eBay, there are some regulations that online shoppers must obey if they want to list their products online. It can be found that all six similar moves are mandatory. On the seller's website, some information about the product must be included in the product detail page: the product title, specifications, and features, delivery time and shipping transportation, acceptable payment, return policy and etc. There is no wonder why Chinese and American eBay stores would share six similar moves.

\subsubsection{Cultural reasons_- cultural dimension theory}

As for the different moves analyzed above, some distinctive differences can be explained by Hostede's (1980) cultural dimension theory. This theory is a framework for cross-cultural communication which aims for making explanations on the differences that existed in among different cultures. Hofstede (1980) proposed four original cultural dimensions based on a large amount of data collected from his rich individual experience, which are power distance, uncertainty avoidance, individualism \& collectivism, and masculinity \& femininity. And then, in 1992, Minkov and his colleagues added the fifth dimension, that is, long-term \& short-term orientation, and the sixth one, called indulgence \& restraint. 
The individualistic cultural society, like the United States, focuses more on personal achievement, and the interpersonal relationship in this society is very loose. The nature of pursuing individualism makes Americans apply various forms or styles to help make the product description more creative and diversified in formats, language arrangement, and whole website design, thus can show more content and ideas to potential consumers. Conversely, the collectivistic cultures prefer to put more emphasis on the advancement of the community or the whole society, so people who live in this society would be more likely to follow the trend to state their missions and values, that's the reason that Chinese e-stores employ the same template in stating their product description, which resulting in the relatively rigid form of Chinese online product description. Therefore, American sellers would put the hyperlinks of their e-store and hot-sale products in the online product description, it is an effective method to increase customer traffic and conversion rate. In the contrast, according to the author's working experience in a large Chinese cross-border e-commerce company, Chinese sellers would not put such hyperlinks in product detail page, because they used to only put the fixed product description prepared by their company, these sellers would rather put thousands of product listings in a very short time than focusing on one competitive product. By this method, it is hard for an eBay store to launch a hot-sale product. But now, Chinese cross-border e-commerce enterprises have begun to change their marketing strategies.

Individualist supremacists regard self-esteem and arrogance as signs of personal mental health. Therefore, Americans will never belittle themselves in order to show humility but often boast and promote themselves. However, Chinese people living in a collectivistic value environment rarely boast about themselves. By comparing the product description of American and Chinese estore on eBay, it is worth noting that only some American eBay stores would apply a short sentence to emphasize the advantage of their listing products, while Chinese e-stores would not.

The uncertainty avoidance dimension relates to the degree to which individuals of a specific society are comfortable with uncertainty and unknown. Countries displaying strong uncertainty avoidance believe and behave in a strict manner. Citizens in this society will avoid unconventional ways of thinking and behaving, they will try their best to minimize the occurrence of uncertainty and unusual circumstances and to proceed with changes step by step. Those countries or societies with a low uncertainty avoidance index would display more ease in regard to uncertainty and unknown, people belonging to this society tend to be more tolerant of change. According to Hofstede's theory, the Chinese belong to be a society with high uncertainty avoidance index, they prefer not to break the current rule, so in the similar template used in writing product descriptions, Chinese e-shoppers would not add personal characteristics in their e-stores. Oppositely, America is a society of low uncertainty avoidance index, therefore, American e-shoppers would rather arrange more unique features to polish their product description.

About the differences in format adoption frequency, they are influenced by the different thought patterns between easterners and westerners. In 2003, Nisbett said that to the Asians, the world is a complex place, composed of continuous substances, understandable in terms of the whole rather than in terms of parts. While to westerners, the world is a relatively simple place, composed of concrete objects that can be understood without undue attention to context. In other words, the easterners' thought pattern is more comprehensive than the westerners, they will investigate and probe into the deep meaning of context. In the contrast, affected by the linear thought pattern, westerners would pay greater attention to ethics, morality, intuition, comprehension, rationality, and logic. This difference in thinking pattern leads that Chinese e-shoppers prefer to employ shorter expressions, they expect their customers would dig out more information beyond the literal words. However, those American eBay stores would provide product descriptions as many as possible in order to offer a more complete and visualized understanding of the product description. This phenomenon can also be explained by high\&low context culture theory which is popularized by Edward Hall in 1959 in his book The Silent Language. High-context cultures often exhibit less direct verbal and nonverbal communication, utilizing small communication gestures and reading more meaning into these less-direct messages. Countries that fall into this categorization include China. Low-context cultures do the opposite, direct verbal communication is needed to properly understand a message being communicated and relies heavily on explicit verbal skills. Some of the cultures that fall into this low-context communication are western cultures like the United States.

\subsubsection{The negative comments}

Are those product descriptions adapted according to the corresponding negative comments consumers left? In order to figure out whether the negative comments for face masks play a pivotal role for the e-store owners in designing their product description, this paper also collected all the negative comments left for the face masks in the above 20 eBay e-stores. And all these negative comments are categorized according to the messages customers left on the comment interface.

All the negative data can be shown in the following two pie charts so as to more clearly about the distribution of each kind of reasons consumers left their negative comments in Chinese and American eBay e-stores:

By comparing these two pie charts, various reasons for consumers to leave negative comments for face masks in Chinese and American eBay e-store are clear to be analyzed. 
In the first pie chart, it shows that two reasons including non-delivery and fake description take $55 \%$ proportion in all 9 reasons that customers left negative comments, $28 \%$ of the negative comments left because consumers did not receive their goods in the promised time, while $27 \%$ of these negative comments left because some consumers thought that the goods they received were not the same as the product description, they felt cheated.

It is no wonder that the red bold notice message reminds customers to notice the subtle difference between the online description and the real product. Those Chinese e-shoppers on eBay try to avoid their responsibilities after adding this extra move. Conversely, fake description (only 9\%) is not a hard nut to crack in the negative comments. So those American eBay shoppers do not have to add this extra move.

\section{The reasons consumers left negative comments in Chinese e-store}

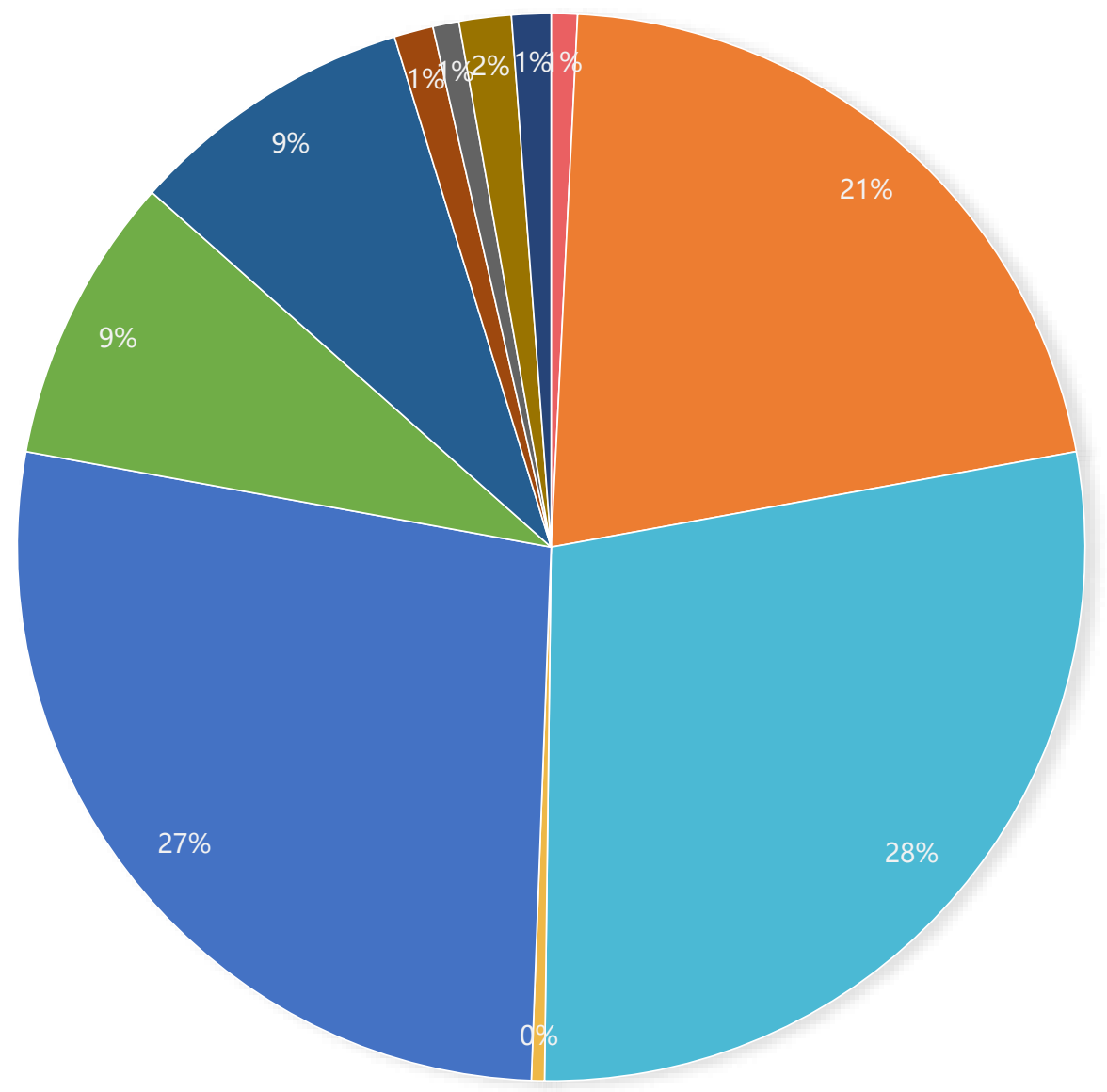

- Unsatifactory Package

- Unsatifactory Quality

- Non-delivery

घany Orders in One Package

- Fake Description

- Without Specific Reasons

- Missing Order

- Wrong Order

- Order cancelled but has been delivered

- Unsatifactory Communication with seller

- Damaged Package 


\section{The reasons consumers left negative comments in American e-store}

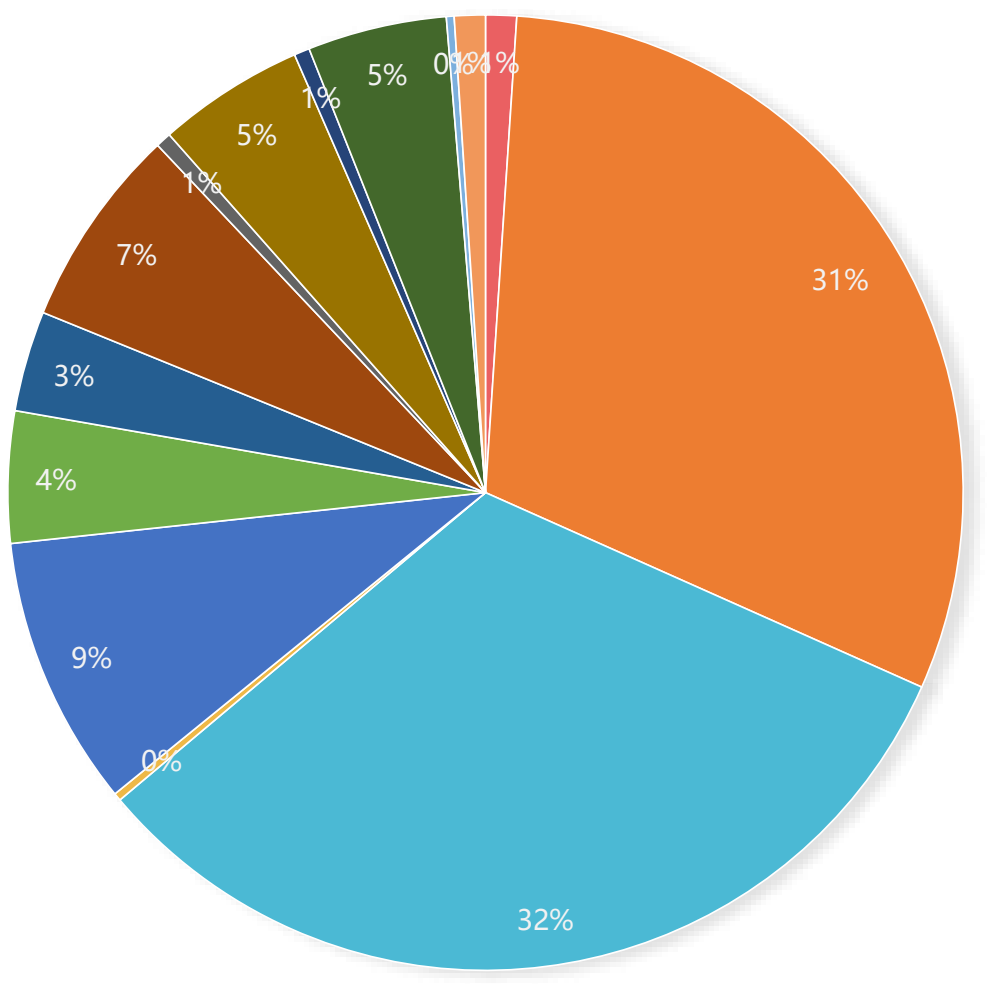

- Unsatifactory Package

- Non-delivery

- Fake Description

- Missing Order

- Order cancelled but has been delivered - Unsatisfactory Communication

- Damaged Package

- Seller cancelled order
- Unsatisfactory Quality

- Many Orders in One Package

- Without Specific Reasons

- Wrong Order

- Seller refused to refund

- High Transportation Fee

It is noticed that in the second pie chart, $32 \%$ of the negative comments left for face masks in American eBay store because of non-delivery, which taking up the biggest share in all 12 reasons, the same goes to the Chinese eBay store.

According to the author's working experience in a Chinese eBay enterprise, most of the Chinese eBay stores will not deliver their goods to Chinese consumers, their targeted customers are Americans, British or other westerners, so the average goods delivery time would be over 20 days, and some of them would be missed or damaged during the long-period transportation, but sellers promised that the delivery time would be within 20 days, so when the consumers sent emails for the customer service agents to ask them the accurate delivery time, those agents won't tell customers the truth because the agents have to control the refund rate. As for the American eBay e-stores, their targeted consumers are exactly Americans, so their consumers' expected delivery time would be less than 14 days, the missing package would be also expected to be less than a package from abroad.

By comparing these two pie charts, it is interesting to find that there are three more reasons in American eBay stores than in Chinese, including seller refuses to refund, seller canceled order and high transportation fee. It seems that Chinese sellers would rather refund their consumers instead of getting a negative comment from their consumers because the positive ratio is very important to keep the store's influx of customers and the e-store's development. And it is noticed that every Chinese eBay enterprise would appoint an after-sale service agent to contact the consumers who left negative comments in order to ask for 
those customers to change their negative comments into positive ones. Therefore, they pay more attention to negative comments than American sellers, and they will list out the refund policy so consumers will contact first the agent instead of leaving negative comments directly. $5 \%$ of American stores' negative comments for face masks left because sellers refuse to refund, then there is no wonder why American sellers would not add their refund policy in Return Move (Move 6).

Another extra reason for leaving negative comments in the American eBay store is unsatisfactory communication with the seller, which accounts for $5 \%$, while in the Chinese eBay store, it only accounts for $3 \%$, and most of them happened because of jet lag. By combing the analysis of reasons for negative comments with the analysis of move structures, it can be found that Chinese sellers could provide effective after-sale communication to avoid any possible negative comments, in their move structure of product description, Move 9 Contact us is mandatory, while in American eBay store, this move is optional. In fact, e-mail is the most effective approach for communication between sellers and consumers on eBay

\section{Conclusion and implication}

This study has investigated the move employed in the product description of Chinese and American e-store on eBay. The data collected from one of the biggest $\mathrm{C} 2 \mathrm{C}$ cross-border e-commerce platforms have revealed some features that can elucidate ways of increasing commodity conversion rates for Chinese and American sellers on eBay. 7 moves have been analyzed in the data collected in the product description of American eBay stores and 9 moves from Chinese. By comparing and contrasting these moves, this paper figures out the similarities and differences of moves applied in the product description of Chinese and American eBay stores.

Because of the listing product regulation on eBay, the similarities between Chinese and American product descriptions would occur inevitably, including product title, product detail or specifications, product features and functions, payment, shipping, delivery time, mode of transportation, and return policy.

Hofstede's cultural dimension theory is acted as conduction to investigate the reasons behind the differences manifested between the product description of Chinese and American eBay stores in the move structures chosen. It can be found that collectivistic cultures like China are less likely to be creative in the design of product descriptions, while the individualistic culture like the United States will put more personal characteristics in their move structures of the product description. Unlike the American eBay sellers, Chinese eBay sellers put greater value on consumers' negative comments, most of them will polish the move structures of their product description in order to avoid any possible negative comments.

On the basis of the results of this study, it makes an analysis of the moves of the product description, which enlarges the related research scope of the study of move analysis. Practically, this research could provide some implications for Chinese eBay stores or other cross-border e-commerce platforms to write their product description better. Firstly, it is urgent for Chinese merchants working on cross-border e-commerce to make their product description more realistic; secondly, the product detail page of Chinese sellers has to be more featured, the unified template to produce a large amount of product description needs to be banned, the business pattern of launching thousands of product listing once should be changed into listing a few products with competitive quality.

Funding: This research received no external funding.

Conflicts of Interest: The authors declare no conflict of interest.

\section{References}

[1] Bhatia, V.K. (1986). Speech Genre and Other Later Essays. Austin: Texas University Press.

[2] Bhatia V.K. (1993). Analyzing Genre: Language Using in Professional Settings. London: Longman.

[3] Bonyadi A. (2012) Genre Analysis of media texts. Procedia-Social and Behavioral Science. 66, 86 96.

[4] Deng, Y. (2019). Comparative study on business models of Amazon and Alibaba B2C cross-border e-commerce platforms. (Master's thesis, Lanzhou University of Finance and Economics).

[5] Duan, W.Z. (2014). Online store operation practice. China University of Science and Technology Press

[6] "eBay Marketplace Q3 2020". https://www.ebayinc.com/impact/reports-policies/

[7] Hofstede, G., Hofstede, G. J., \& Minkov, M. (2010). Cultures and organizations: Software of the mind: Third Edition. New York: Mcgraw-hill.

[8] Ji, Y. (2020). Discourse analysis of commodity details from the perspective of Systemic Functional Linguistics (Master's thesis, central China Normal University).

[9] Kessler, M. (2020). A text analysis and gatekeepers' perspectives of a promotional genre: Understanding the rhetoric of Fulbright grant statements. English for Specific Purposes, 60, 182-192.

[10] Liu, W. Q. (2006). Sino American cultural differences and cross-cultural communication in business activities. Journal of Hubei University of EConomics (HUMANITIES AND SOCIAL SCIENCES EDITION) (07),96-97.

[11] Liu, X.Y. (2016). A genre comparative analysis of corporate mission statements of cross-border e-commerce platforms between China and the United States (Master's thesis, Guangdong University of Foreign Studies).

[12] Lu, W. Y. (2019). Research on taking advantage of marketing strategy in the design of commodity details page. The Chinese market, 33. 
[13] Luo, Y. J. (2017). Discourse analysis of copywriting on the product details page of the e-commerce platform. Journal of culture (11), 158-160

[14] McCarthy, E. J., Shapiro, S. J., \& Perreault, W. D. (1979). Basic marketing (pp. 29-33). Ontario: Irwin-Dorsey.

[15] McKay J, Marshall P. (2004). Strategic Management of E-business. John Wiley \& Sons, Brisbane.

[16] Rutherford, B. A. (2013). A genre-theoretic approach to financial reporting research. The British Accounting Review, 45(4), $297-310$.

[17] Swales, J. (1990). Genre analysis: English in academic and research settings. Cambridge University Press.

[18] Swales J. (2004) Research Genres: Explorations and Applications. Cambridge University Press. 2004

[19] Wang, Q. (2020). A contrastive analysis of moves in the discussion part of English academic papers by Chinese and foreign scholars. (Master's thesis, Changchun University of Technology)

[20] Xu, X., \& Lockwood, J. (2021). What's going on in the chat flow? A move analysis of e-commerce customer service web chat exchange. English for Specific Purposes, 61, 84-96.

[21] Yelland, C. (2011). A genre and move analysis of written feedback in higher education. Language and Literature, 20(3), $218-235$.

[22] Zhong, P. J. (2016). On optimizing the details page to improve commodity conversion rate. Mall modernization (13), 5-6

[23] Zuo, R. R., and Ye, W. J. (2020). Optimization skills of product details page in the context of cross-border e-commerce B2B -- Taking Alibaba international station platform as an example. Foreign economic and trade practice. 